\title{
A RELEVÂNCIA DOS ASPECTOS EMOCIONAIS DO DEFICIENTE FÍSICO PARA A INCLUSÃO NO AMBIENTE DE TRABALHO
}

\author{
Joselene Lopes Alvim, Valdecir Cahoni Rodrigues \\ Universidade do Oeste Paulista - UNOESTE, Curso Tecnólogo em Gestão de Recursos Humanos, Presidente Prudente, \\ SP.E-mail: joalvim@unoeste.br
}

\section{RESUMO}

Toda empresa que busca ser reconhecida por sua responsabilidade social deve investir em funcionários com deficiência, atitude esta que leva a uma diminuição da desigualdade social e cultural. Em uma era de valorização do capital intelectual, o reconhecimento do colaborador é imprescindível para o sucesso da organização. No caso do indivíduo com deficiência ainda há barreiras que dificultam a sua inclusão dentro do ambiente organizacional. O presente trabalho objetivou descrever a importância do reconhecimento das emoções do colaborador com necessidades especiais, particularmente a física. Foi feita uma breve revisão da literatura a respeito do significado de imagem corporal e autoconceito, bem como das manifestações psíquicas e comportamentais desencadeadas. A interação social e o reconhecimento dos valores que compõe o sujeito, e que extrapola a dimensão física, é de suma importância para o desenvolvimento da sua autoestima, da motivação e, consequentemente, de sua produtividade.

Palavras-chave: Responsabilidade social. Deficiente físico. Inclusão. Imagem corporal. Subjetividade.

\section{THE RELEVANCE OF EMOTIONAL ASPECTS OF INDIVIDUAL WITH DISABILITIES FOR INCLUSION IN THE WORKPLACE}

\begin{abstract}
Every company that seeks to be recognized for its social responsibility should invest in employees with disabilities, this attitude which leads to a decrease in social and cultural inequality. In an era of intellectual capital, recognition of employees is essential to the success of the organization. If the individual with disabilities there are still barriers to their inclusion within the organizational environment. This study aimed to describe the importance of recognizing the employee's emotions with special needs, particularly physics. A brief review of the literature on body image and self-concept of meaning as well as the psychological and behavioral manifestations triggered was made. Social interaction and recognition of the values that make up the subject, and that goes beyond the physical dimension, it is of paramount importance for the development of self-esteem, motivation and hence their productivity.
\end{abstract}

Keywords: Social responsibility. Handicapped. Inclusion. Body image. Subjectivity. 
INTRODUÇÃO

A inclusão tem sido a palavra de ordem na sociedade e, consequentemente, para uma cidadania plena. É um processo que abarca o reconhecimento do indivíduo integralmente, seja em sua identidade, gênero, etnia, condição social, crença religiosa, deficiências, necessidades e potencialidades.

Ao longo da história, a relações sociais das pessoas com o deficiente eram determinadas de acordo com as características econômicas, sociais e culturais de cada época, refletindo crenças, valores e ideologias (FRANCO \& DIAS, 2005). A estrutura das sociedades marginalizava-os, privando-os de qualquer tipo de liberdade.

Nas últimas décadas, movimentos nacionais e internacionais têm promovido e implementado a inclusão nas escolas regulares com motivos fundamentados em critérios de justiça e igualdade. No entanto a maior conquista para a Organização das Nações Unidas para a Educação, a Ciência e a Cultura (UNESCO) foi a Conferência Mundial de Educação Especial, em Salamanca, na Espanha, em 1994, estabelecendo que as crianças com deficiência devam ser incluídas em uma Educação para Todos, em seu âmbito mais amplo (MACIEL, 2000).

Porém, mesmo com a ampliação da atitude de inclusão, fortalecida pela Declaração de Salamanca, na Espanha, em 1994, não foi suficiente para determinar o fim da marginalização dos indivíduos com deficiência. Como em toda mudança, há resistências. Portanto, o processo exige a reavaliação de antigas crenças e uma reflexão profunda sobre o papel da educação e da sociedade em geral, enquanto formadora de cidadãos.

\section{METODOLOGIA}

Considerando que "a investigação científica depende de um conjunto de procedimentos intelectuais e técnicos" (GIL,2006, p. 26), uma pesquisa só é possível e válida através da aplicação de métodos científicos, por isto este artigo foi construído a partir de abordagem qualitativa, onde o olhar subjetivo predominou ao invés do meramente racional. Tendo em vista que "a pesquisa qualitativa se preocupa com aspectos da realidade que não podem ser quantificados, centrandose na compreensão e explicação da dinâmica das relações sociais". (FONSECA, 2002, p.20). Como instrumento de coleta de dados foi utilizado a pesquisa bibliográfica, que segundo Marconi e Lakatos (1991, p. 183):

[...] abrange toda bibliografia já tornada pública em relação ao tema de estudo, desde publicações avulsas, boletins, jornais, revistas, livros, pesquisas, monografias, teses, material cartográfico etc., até meios de comunicação orais: rádio, gravações em fita magnética e audiovisuais: filmes e televisão. 
Sendo assim, a este tipo de pesquisa abrange todas as fontes bibliográficas publicadas anteriormente e que fazem referencia ao assunto em estudo. Neste caso, foi realizada uma pesquisa em livros, bem como em artigos eletrônicos para dar fundamentação teórica a este trabalho.

\section{RESULTADOS}

\section{A lei de cotas}

De acordo com os dados coletados pelo Instituto Brasileiro de Geografia e Estatística IBGE, no censo demográfico de 2010, há no Brasil 45, 6 milhões de pessoas com pelo menos um tipo de deficiência: motora, visual, auditiva, intelectual ou mental, sendo que este número que corresponde a $23,9 \%$ da população total.

Nos debates atuais sobre inclusão, o fundamento ideológico tem como base a Declaração Universal dos Direitos Humanos que deve garantir ao individuo uma vivência não segregadora, e que os integre à sociedade. A Constituição Federal de 1988, no artigo 93 institui a "reserva de mercado ou sistema de quotas", conhecida como a Lei de Cotas, pelo qual estabelece que as empresas com mais de cem empregados devam reservar uma parcela de seus cargos para que sejam preenchidas por pessoas com deficiências, possibilitando assim o direito das pessoas com deficiência de ingressar no mercado de trabalho. Caso a empresa não contrate ela deve justificar sua decisão de forma clara e objetiva e não subjetiva.

Mesmo com toda determinação do Ministério do Trabalho para amparar os direitos deste trabalhador com deficiência conscientizando a sociedade em geral, observa-se que há empresas que passaram a contratar tais indivíduos apenas após a obrigatoriedade da Lei de Cotas, como cumprimento legal. Outras compreendem a lei como um compromisso social, mas justificam a dificuldade em contratá-los devido ao baixo grau de escolaridade ou qualificação profissional destes indivíduos ou até mesmo pelas limitações de acessibilidade nestes espaços organizacionais.

Ainda que promover esta diversidade pode trazer muitos benefícios para a empresa, observa-se que há muita resistência por parte dos gestores, e também de alguns colaboradores, por não saber lidar com os mesmos, numa clara demonstração do quanto muitas pessoas têm dificuldade em lidar com as diferenças. A explicação reside na própria História onde os deficientes foram segregados, marginalizados do convívio social, e inclusive escolar, durante muitos séculos. 
Um olhar atento sobre a inclusão

Assim, o conceito de inclusão, abarca também uma proposta mais ampla que vai além do planejamento e construção de políticas públicas de educação, da implantação de programas de apoio. Estas ações podem atender a uma exigência legal, no entanto, na prática, e sob o ponto de vista ético, não significa o reconhecimento da igualdade de direitos deste deficiente, enquanto cidadão. A educação inclusiva, dentro da empresa, da sociedade como um todo, prioritariamente, deve assumir a função de ensinar a aceitação do outro, o respeito às diferenças, a alteridade.

Lopez (2004) pontua que independente do tipo de dificuldade ou limitação que o individuo apresente, do rendimento, focalizar a atenção no bem-estar emocional e social é imprescindível.

Uma enfermidade incapacitante, seja ela congênita ou adquirida, desencadeia no indivíduo uma série de reações que muitas vezes não são compreendidas pelas pessoas que convivem com ele, seja em suas relações familiares, sociais ou escolares. Assim, a priorização do papel formativo sobre o informativo deve incluir, fundamentalmente, a compreensão dos aspectos emocionais que permeiam a pessoa com necessidades especiais. Este entendimento humaniza a relação entre gestor e colaborador.

Ainda que existam muitas lacunas e barreiras que dificultam a inclusão dentro do ambiente organizacional,o objetivo deste trabalho não é pontua-las, tampouco comentar as contradições de posicionamento existentes, e sim descrever a importância do reconhecimento da subjetividade, das emoções do colaborador com deficiência, particularmente a física.

Em uma era de valorização do capital intelectual, reconhecimento do colaborador é imprescindível para o sucesso da organização. Para isto é preciso ver este colaborador além de um corpo físico. Isto promove segurança não apenas para o colaborador com deficiência, mas na empresa como todo, dos integrantes que reconhecem a responsabilidade social da mesma, num processo que certamente resulta em mais integração e identificação com a organização.

\section{O conceito}

Em tempos de politicamente correto, o conceito de deficiência mostra-se impreciso, apresentando variações quanto ao modelo médico, descrito inicialmente, e ao modelo social, descrito posteriormente, o que dificulta uma única utilização do termo pela sociedade.

Silva (2009) discorre sobre o cuidado da linguagem quando o assunto é deficiência, enfatizando que os termos "portador de deficiência" e "pessoas com necessidades especiais" não são adequados para utilizar. A autora esclarece que a palavra "portador" implica em algo que se porta ou que se carrega e, por conseguinte, é passageiro, temporário; e a deficiência é algo 
permanente; e "pessoas com necessidades especiais", ela considera amplo, afinal qualquer pessoa, segunda a referida autora, tem necessidades especiais, independente de apresentar ou não algum tipo de deficiência. A partir de 1981, Silva (2009) coloca que, por determinação das Organizações das Nações Unidas (ONU), passou-se a utilizar o termo "deficiente" e por volta da metade da década de 1990, até os dias atuais, utiliza-se "pessoas com deficiência".

É mister salientar que, mais do que avaliar os termos, o individuo não deve ser reduzido a sua deficiência e sim reconhecido como pessoa, acima das suas restrições. Em síntese, a inclusão social defende, simultaneamente, a igualdade e a diferença.

\section{Imagem corporal e autoconceito}

A construção da imagem corporal compreende processos psicológicos, emocionais, fisiológicos, cognitivos e sociais na relação do indivíduo com o meio, sendo um aspecto importante da identidade pessoal (TAVARES, 2003). É um processo único, subjetivo porque envolve fatores como o ambiente em que ele está inserido, seus valores, suas crenças, suas marcas singulares. A imagem corporal é um dos aspectos psicológicos associados à aceitação do próprio corpo, resultando em uma autoestima positiva ou negativa, dependendo da forma como o individuo se vê. O autoconceito é influenciado por muitas variáveis, segundo Sisto e Martinelli (2004), como a família, idade, meio social, raça, gênero e aspectos físicos. As bases que mais predominam são as sociais e as relacionais. $\mathrm{O}$ autoconceito social é a percepção que o indivíduo tem sobre o quanto as pessoas gostam dele, da própria percepção acerca da aceitação social.

Desta forma, é de sua importância considerar o complexo universo de influências que o individuo recebe e as interações que ele estabelece com o meio, uma vez que o ambiente, seja o social, familiar ou escolar, forma e modula seu autoconceito.

\section{Manifestações psíquicas e comportamentais}

Aceitar a situação frustradora é um processo penoso. O sujeito utiliza-se de modos primitivos para lidar com a angústia. Afasta-se da realidade, como forma de não sofrer, refugiando-se, inicialmente, no mundo da fantasia, seja no todo ou em parte (FREUD, 1911). A religião apresenta-se também como uma forma de proteção contra esta realidade. É uma barganha, uma forma de lidar com o sofrimento. Neste sentido, ocorre muitas vezes do sujeito acreditar no poder do destino, que aparece como uma entidade julgadora, punitiva. O sujeito considera que cometeu um pecado e será punido pelas forças do Destino ou dos Deuses. Dessa 
forma pode ocorrer uma resignação por parte do indivíduo que, por acreditar ser merecedor desta "Punição Divina", nada faz para ressignificar a perda.

Apesar das reações frente a uma perda não serem padronizadas e sim de acordo com a singularidade de cada um, do modo como o individuo constituiu a sua existência, há algumas características psíquicas comuns possíveis de pontuar. É possível observar no sujeito estados frequentes de depressão, insatisfação, insegurança, reações de agressividade vinculadas à frustração, bem como reações substitutivas de ansiedade, impaciência, hipoatividade, inveja, vulnerabilidade, mau-humor e sentimentos de menos-valia. Ele busca algumas vezes isolamento, retirando-se do convívio social. Defesas presentes como a negação, compensação, projeção, regressão, formação reativa, evidenciam o excesso de angústia que o ego apresenta, buscando nas defesas uma forma de aliviar a tensão, amenizando o conflito interno (ANGEROMI-CAMOM, 2003).

Definir enfermidade não significa simplesmente identificar as modificações dos sinais físicos, as sequelas, prognósticos, etc. Implica também, e principalmente, uma reflexão sobre a mudança de sua identidade e as questões emocionais. Sabe-se que um indivíduo, diante de uma enfermidade incapacitante, tem que modificar estilos de vida, porém não é tão simples assim, pois nesta troca está a constituição de uma personalidade que estará deixando para o resto da vida.

A crise da identidade é uma das principais dificuldades que o indivíduo enfrenta. Há perdas de referenciais significativos para o sujeito, como sua rotina de vida, autonomia, etc. Essa dificuldade de autonomia, de ter que depender do outro para concluir determinadas tarefas, pode suscitar no sujeito sentimentos de desconfiança em relação ao meio externo, as pessoas que o cercam.

Seu espaço vital não é algo que depende apenas de si, de sua escolha e isso pode afastá-lo das oportunidades normais de realização, uma vez que a incapacidade representa limites de ação e de expansão pessoal.

Como a convivência social torna-se difícil para este indivíduo, o mesmo acaba restringindose à família, como uma forma de se sentir protegido deste mundo que agora lhe parece tão diferente. A família, neste processo, desempenha um papel fundamental, uma vez que ela pode ser tanto um facilitador para a reabilitação, a reintegração social e para o reconhecimento de sua limitação, como também um agente de doença à medida que não aceita a situação e desencadeia um processo que vai da culpabilização à superproteção, dificultando ainda mais para o indivíduo o seu novo estado físico. 
É importante salientar que os aspectos emocionais descritos até aqui variam de indivíduo para indivíduo. As reações às perdas vão depender do significado, da representação que o sujeito atribui à parte afetada. Assim não é a incapacidade o aspecto mais significativo numa frustração, e sim o que ela representa.

\section{Responsabilidade Social}

Um dos aspectos mais visíveis do movimento gerado em torno dos deficientes físicos, nos últimos anos, é a responsabilidade social, que tem-se traduzido em adoção de práticas que extrapolam os deveres básicos das organizações.

Assim Responsabilidade Social não é apenas uma ação de filantropia e sim estratégias pensadas para orientar as ações das empresas em consonância com as necessidades sociais, de modo que a empresa garanta, além do lucro e da satisfação de seus clientes, o bem estar da sociedade. Uma vez que empresa esta inserida na sociedade e seus negócios dependerão de seu desenvolvimento, este deverá ser duradouro. É um comprometimento. DIAS (2007).

A longo prazo muitas são as vantagens que um Programa de Responsabilidade Social pode trazer para a organização como, por exemplo, a inclusão de deficientes físicos no quadro de colaboradores. Alguns mercados estão impondo condições para que somente empresas com determinados pré-requisitos possam deles participar. Os benefícios são vários e dentre eles podese destacar uma melhoria na imagem da empresa e na relação desta com os funcionários, clientes, fornecedores, vizinhos e a fiscalização. Os funcionários passam a terem orgulho de trabalharem em uma empresa reconhecida por sua atitude social. Os clientes conscientes acabam procurando por produtos fabricados por empresas que respeitam esta diversidade.

\section{CONCLUSÕES}

Mesmo com as novas propostas sociais, fundamentadas na lei, a flexibilidade organizacional, os materiais adaptados, os procedimentos avaliativos de desempenho e de aprendizagem, além do aprimoramento da equipe de apoio, ainda não são suficientes para o êxito da inclusão. É de suma importância, sobretudo, a interação social e o reconhecimento dos valores que compõe o sujeito, e que extrapola a dimensão física, para o desenvolvimento da sua autoestima e, consequentemente, de sua produtividade

Respeitar a individualidade é respeitar a alteridade, ou seja, é compreender que o homem social interage e interdepende do outro. A partir da compreensão dos aspectos emocionais que constituem o mundo subjetivo dos colaboradores com algum tipo de deficiência, é possível auxilia- 
los a desenvolver suas potencialidades, reconhecendo-os na sua integralidade e não reduzi-los as suas próteses, cadeiras ou aparelhos. Conhecer como este sujeito processa a representação de sua imagem corporal, possibilita o aproveitamento das suas competências individuais para uma melhor aprendizagem e inserção social.

A limitação não é o único aspecto a ser considerado no indivíduo e rejeita-los ou superprotege-los só invalidará seus esforços. Estimulá-los deve ser o objetivo básico da organização.

\section{REFERENCIAS}

ANGERAMI-CAMON, V. (Org.). E a psicologia entrou no hospital. São Paulo: Pioneira, 2003.

BRASIL. Lei n. 8.213, de 24 de julho de 1991. Dispõe sobre os planos de benefícios da Previdência Social e dá outras providências. Brasília, DF, 1991. Disponível em http://www010.dataprev.gov.br/sislex/paginas/42/1991/8213.htm. Acesso em: 12 jul. 2015.

DECLARAÇÃO UNIVERSAL DOS DIREITOS HUMANOS. Adotada e proclamada pela resolução $217 \mathrm{~A}$ (III) da Assembleia Geral das Nações Unidas em 10 de dezembro de 1948. Disponível na Biblioteca Virtual de Direitos Humanos da Universidade de São Paulo: www.direitoshumanos.usp.br. Acesso em: 14 jul. 2015.

DIAS, R. Gestão Ambiental: Responsabilidade social e sustentabilidade. São Paulo: Atlas, 2007.

FONSECA, J. J. S. da. Metodologia da pesquisa científica. Fortaleza: Universidade Estadual do Ceará, 2002.

FRANCO, JR. D. T. A pessoa cega no processo histórico: Um breve percurso. Revista Benjamin Constant. 30: 1-9, 2005.

FREUD, S. (1911). Formulações sobre os dois princípios do funcionamento mental. In: FREUD, S. Obras completas. Rio de Janeiro: Imago, 1996. vol. XII.

GIL, A. C. Como elaborar projetos de pesquisa. 4ạ ed. São Paulo: Atlas, 2006.

INSTITUTO BRASILEIRO DE GEOGRAFIA E ESTATISTICA. IBGE e CORDE encontro internacional de estatísticas sobre pessoas com deficiência. Disponível em:

http://www.ibge.gov.br/home/presidencia/noticias/noticia_visualiza.php?id_noticia=438\&id_pagi na=1 acesso em:10 jul. 2015.

LAKATOS, E. M., MARCONI, M. A. Fundamentos de metodologia científica. 3. ed. São Paulo: Atlas, 1991.

LÓPEZ, F. Problemas afetivos e de conduta na sala de aula. In: COOL, C. PALÁCIOS, J.MARCHESI, $A$. (org.) Desenvolvimento Psicológico e Educação: Transtornos de desenvolvimento e necessidades especiais. Vol 3, 2a ed. Porto Alegre: Artmed, 2004. 
MACIEL, M. R. C. Portadores de deficiência: a questão da inclusão social. São Paulo Perspec., São Paulo , v. 14, n. 2, June $2000 \quad$. Available from $<$ http://www.scielo.br/scielo.php?script=sci_arttext\&pid=S010288392000000200008\&lng=en\&nrm=iso>. Acesso em: 02 Jan. 2014. http://dx.doi.org/10.1590/S0102-88392000000200008.

MINISTÉRIO DO TRABALHO E EMPREGO. A inclusão de pessoas com deficiência no mercado de trabalho. - 2a Edição - Brasília: MTE, SIT, 2007. Disponível em:

http://www.mte.gov.br/fisca_trab/inclusao_pessoas_defi12_07.pdf acesso em: 08 jul. 2015.

SILVA, M. O. E. da. Da Exclusão à Inclusão: Concepções e Práticas. Rev. Lusófona de Educação, Lisboa, $\quad$ n. 13, $2009 . \quad$ Disponível em <http://www.scielo.gpeari.mctes.pt/scielo.phpscript=sci_arttext\&pid=S1645$72502009000100009 \& \operatorname{lng}=$ pt\&nrm=iso>. Acesso em: 01 jan. 2014.

SILVA, M.I. Por que a terminologia "pessoas com deficiência"? Sensibiliza. Disponível em: http://www.prograd.uff.br/sensibiliza/por-que-terminologia-pessoas-com-deficiencia. Acesso em: 03 jan.2014.

SISTO, F. F.; MARTINELLI, S. C. Estudo preliminar para a construção da escala de autoconceito infanto-juvenil (EAC-IJ). Interação em Psicologia, v. 8, n. 2, 2004.

TAVARES, M. C. G. C. F. Imagem corporal: conceito e desenvolvimento. São Paulo: Manole, 2003. 